\title{
A quantum-chemistry approach to the electro-oxidation mechanism of adsorbed carbon monoxide on platinum single-crystal clusters
}

\author{
G. Estiú, S. Maluendes, E.A. Castro and A.J. Arvia \\ Instituto de Investigaciones Fisicoquimicas Téricas y Aplicadas (INIFTA), Facultad de Ciencias Exactas, \\ Universidad Nacional de La Plata, Sucursal 4, Casilla de Correo 16, 1900 La Plata (Argentina)
}

(Received 14 March 1989; in revised form 30 October 1989)

\begin{abstract}
A molecular orbital interpretation of the electro-oxidation of $\mathrm{CO}$ adsorbed on $\mathrm{Pt}$ (100) and $\mathrm{Pt}$ (111) single-crystal clusters, based on the extended Hückel method, is presented. The metal surfaces are simulated with different $(\mathrm{Pt})_{N}$ clusters $(N=25$ for $\mathrm{Pt}(100)$ and $N=19$ for $\mathrm{Pt}(111))$, and the influence of the applied potential is introduced by properly shifting the energy of the metal valence band. The multiplicity of the voltammetric peaks resulting for the reaction emerges from the potential-dependent stabilization energies of different ensembles of the type $(\mathrm{Pt})_{N}(\mathrm{CO})_{n}(\mathrm{OH})_{m}$ associated with the different $\mathrm{CO}$ coverages and coordination geometries. Data derived from the calculations indicate that only a linearly-bonded $\mathrm{CO}$ adsorbate appears to be most likely one involved in the electrochemical oxidative interactions.
\end{abstract}

\section{INTRODUCTION}

The kinetics and mechanism of $\mathrm{CO}$ adsorption-desorption on platinum have been studied extensively both in the gas phase [1-6] and in solution [7-11]. Knowledge of this process at the molecular level is important in dealing with electrolytic reactions involving $\mathrm{CO}$ adsorbates as it occurs, among others, in the electro-oxidation of some organic fuels, such as methanol, and formic acid.

Surface physics data derived from several experimental techniques (EELS, LEED, IRS, TDS, WF) have demonstrated that $\mathrm{CO}$ is non-dissociatively adsorbed on $\mathrm{Pt}$ (111) and Pt (100), with the carbon atom bonded to the surface in two configurations, namely, a linear and a bridge form of adsorbate [1,3-5]. The linear form appears to be favoured on Pt (111) despite the fact that the binding energies (BEs) for both configurations on Pt (100) are about the same [12]. These results show that the structure of the adsorbate depends on both the nature of the substrate 
and $\theta$, the total degree of $\mathrm{CO}$ surface coverage. Thus, for $\theta=0.33$ on $\mathrm{Pt}(111)$, a $(\sqrt{3} \times \sqrt{3})$ R30 LEED pattern indicates a linear coordination, whereas for $\theta>0.5$, a well-ordered $c(4 \times 2)$ structure which involves one half on-top and one half bridge adsorbate-substrate bonds is formed. Furthermore, for $\theta>0.68$ the greater compression of the $\mathrm{c}(4 \times 2)$ unit mesh in the $(1 \overline{1} 0)$ direction produces a hexagonal close-packed structure, which is assigned to quasi-bridge coordination $[1,4]$. A different behaviour is found on $\mathrm{Pt}(100)$. In this case, when $\theta=0.5$, the adsorbed layer forms a $c(2 \times 2)$ LEED structure through the occupation of bi-coordinated sites. But on increasing $\theta$, a linear coordination is favoured, and from $\theta=2 / 3$ upward the $\theta^{\mathrm{T}} / \theta^{\mathrm{B}}$ ratio rises according to $\theta$, where $\theta^{\mathrm{T}}$ and $\theta^{\mathrm{B}}$ stand for the degree of surface coverage by linear (T) and bridge (B) $\mathrm{CO}$ adsorbate structures, respectively, and $\theta=\theta^{\mathrm{B}}+\theta^{\mathrm{T}}$.

Carbon monoxide dissolved in aqueous solutions can also be adsorbed on platinum [13-19]. This process, which has been studied extensively during the last few years, is much more complicated than $\mathrm{CO}$ adsorption from the gas phase because of the presence of the solvent. As a matter of fact, water can interfere with the adsorbate structure either as a molecule or through its decomposition products, i.e. $\mathrm{OH}$ and $\mathrm{H}$ species [20]. Thence, a number of different new adsorbed species such as $(\mathrm{COH})_{\mathrm{ad}},(\mathrm{COOH})_{\mathrm{ad}},(\mathrm{CO})_{\mathrm{ad}}(\mathrm{OH})_{\mathrm{ad}}$, etc. can be produced.

This situation turns out to be increasingly complicated at the $\mathrm{Pt} / \mathrm{CO}$ (electrolyte solution) interface under the influence of an external electric potential, as the complex structure of the adsorbed layer can also change according to the applied potential. It has been demonstrated recently that negative applied potentials (negatively charged metal) shift adsorbed $\mathrm{CO}$ from one-fold to two-fold and possible three-fold sites on $\mathrm{Pt}(111)$ [21,22] as a result of the shift up in energy of the metal valence band which, in consequence, lies closer to the energy of the empty $\mathrm{CO} \pi^{*}$ orbital level $[12,22,23]$. This fact strengthens the $d-\pi^{*}$ orbital mixing and favours $\mathrm{CO}$ adsorption at highly coordinated sites. Conversely, positive applied potentials result in the stabilization of the one-fold coordination [24], in response to the metal $d$-band lowering that strengthens the $5 \sigma$-metal bond interaction. The same trend has been found for Pt (100). Likewise, for positive potentials (positively charged metal) on both Pt (111) and Pt (100), the adsorbed structure with linearly adsorbed $\mathrm{CO}$ appears to be favoured. Nevertheless, at present, only coordination changes of isolated adsorbed molecules have been calculated as a function of the applied potential.

The voltammetric electro-oxidation of $\mathrm{CO}$ adsorbed on platinum appears as a complex irreversible reaction which depends on the electrolyte composition, $\mathrm{CO}$ adsorption potential, Pt crystalline characteristics and size of the Pt metal cluster in the case of dispersed platinum electrodes [25]. For a given Pt electrode topography and adsorption potential, the multiplicity and position of the $\mathrm{CO}$ electro-desorption peaks, which appear as the fingerprint of the reaction, become highly dependent on $\theta$. Thus, for $\theta=0.5$ the electro-oxidation of adsorbed $\mathrm{CO}$ has two current peaks in the 0.8-1.1 V range (vs. SHE), but a single current peak for $\theta \rightarrow 1$. The kinetics of the electro-oxidation of adsorbed $\mathrm{CO}$ on platinum were basically interpreted in 
terms of a complex mechanism involving two interacting adsorbates, namely $\operatorname{Pt}(\mathrm{CO})$ and $\mathrm{Pt}(\mathrm{OH})$, the latter formed through the direct electro-oxidation of water molecules. The current peak at about $0.8 \mathrm{~V}$ (vs. SHE) was assigned to the electro-oxidation of the bridge-bonded adsorbate $(\mathrm{CO})_{B}$, whereas the current peak close to $1.0 \mathrm{~V}$ was related to the electro-oxidation of the linearly bonded adsorbate $(\mathrm{CO})^{\mathrm{T}}$ [7-9].

The fact that the electro-oxidation of adsorbed $\mathrm{CO}$ on platinum has been studied in considerable detail justifies our attempt to describe it through a quantum-mechanical approach. At this stage, it is interesting to calculate the structures of the different possible CO-containing adsorbates on platinum single-crystal clusters by using the extended Hückel method for the different $\mathrm{Pt}(\mathrm{CO})-\mathrm{Pt}(\mathrm{OH})$ interactions as a function of the applied potential [1-5]. The results offer new perspectives to interpret the adsorbed $\mathrm{CO}$ electro-oxidation reaction by means of the assignments of the corresponding voltammetric peaks to different adsorbates with definite structures. The results derived from the present theoretical approach become of diagnostic value to discriminate among possible reaction pathways.

\section{SUMMARY OF THE CALCULATION PROCEDURE}

Surface modelling was done by following a cluster approach, consisting of $\mathbf{P t}_{19}$ and $\mathrm{Pt}_{25}$ bilayers for $\mathrm{Pt}$ (111) and $\mathrm{Pt}$ (100), respectively (Fig. 1). According to experimental results [18], the nearest-neighbour Pt-Pt distance was fixed at $2.77 \AA$ $(0.277 \mathrm{~nm})$.

The extended Hückel method (EHM) $[26,27]$ was used with the input parameters assembled in Table 1. Diagonal elements of the Hamiltonian matrix are given by the valence orbital ionization potentials of the atomic orbitals (VOIP), while off-diagonal elements were calculated by means of the "weighted $H_{i j}$ formula" [28]. Applied potentials were simulated by either increasing or decreasing VOIP for positive or negative charging, respectively. The resulting shift in the metal $d$ band reproduces the actual electrode charging effect. This approach, which has been used extensively in the semi-empirical treatment of electrochemical systems [29-32] and for the
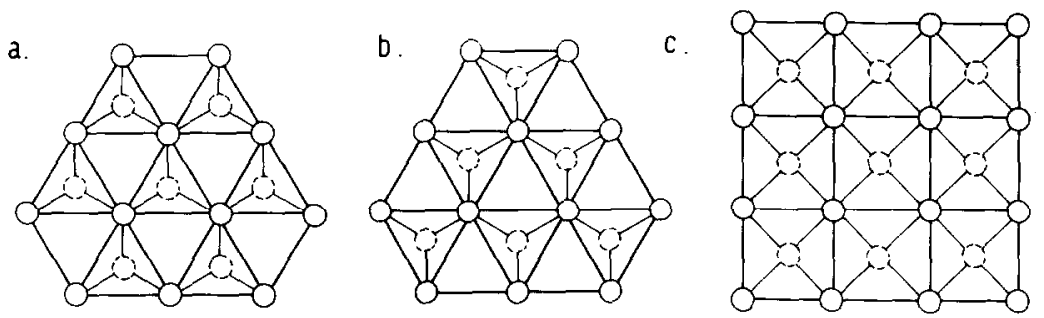

Fig. 1. Metal cluster models for the different Pt surface sites. The full lines represent the topmost surface layer and the dotted lines the second metal layer. (a) Cluster used to model top, bridge and (3-1) hollow single sites on a Pt (111) surface; (b) cluster used to model (3-3) hollow single sites on Pt (111); (c) cluster used to model top, bridge and hollow single sites on Pt (100). 
TABLE 1

Parameters used in EHM calculations for uncharged platinum

\begin{tabular}{llllll}
\hline Orbital & $H_{i i} / \mathrm{eV}^{\mathrm{a}}$ & $\mu_{1}{ }^{\mathrm{b}}$ & $\mu_{2}{ }^{\mathrm{b}}$ & $c_{1}{ }^{\mathrm{c}}$ & $c_{2}{ }^{\mathrm{c}}$ \\
\hline $5 d \mathrm{Pt}$ & -13.520 & 6.013 & 2.616 & 0.6334 & 0.5512 \\
$6 s \mathrm{Pt}$ & -10.930 & 2.554 & & & \\
$6 p \mathrm{Pt}$ & -6.405 & 2.554 & & & \\
$1 s \mathrm{H}$ & -13.600 & 1.300 & & & \\
$2 s \mathrm{O}$ & -32.300 & 2.275 & & & \\
$2 s \mathrm{O}$ & -14.800 & 2.275 & & &
\end{tabular}

${ }^{\mathrm{a}} \mathrm{H}_{i i}$ is the valence orbital ionization potential at the $\mathrm{AO}_{\mathrm{i}}$.

${ }^{b} \mu_{1}, \mu_{2}$ are exponents in the STO.

${ }^{\mathrm{c}} c_{1}, c_{2}$ are coefficients in the double zeta $d$ orbitals of $\mathbf{P t}$.

dopant effect $[12,23]$, provides the correct trend for the variation of the electrode potential.

Repulsion energy terms, including their dependence on both the applied potential and the internuclear distance, were calculated according to Anders et al. [33] for the $\mathrm{Pt}-\mathrm{C}$ and $\mathrm{Pt}-\mathrm{O}$ interactions. The corresponding pairwise additive repulsion energies, $E_{\mathrm{R}}(\mathrm{Pt}-\mathrm{C})$ and $E_{\mathrm{R}}(\mathrm{Pt}-\mathrm{O})$, were obtained by using the following equations [34]:

$E_{\mathrm{R}}(\mathrm{Pt}-\mathrm{C})=497.01186 \exp (-3.199 r) \exp (-0.109 E)$

$E_{\mathrm{R}}(\mathrm{Pt}-\mathrm{O})=35867.970 \exp (-5.977 r) \exp (-0.067 E)$

where $r$ denotes the internuclear distance (in $\AA$ ) for a given pair of atoms and $E$ is the electrode potential (in $\mathrm{eV}$ ) calculated as the difference between $\left|H_{6 s 6 s}\right|$ and the standard $6 s$ VOIP of $\mathrm{Pt}$ in vacuo $(-10.000 \mathrm{eV}$ [35]. Then the $\mathrm{Pt}-\mathrm{CO}$ and $\mathrm{Pt}-\mathrm{OH}$ adsorption distances were optimized semi-empirically throughout the geometry, furnishing the minimum energy.

It should be noted that the parameters assembled in Table 1 are not exactly the same as those used in previous publications [29,30]. In early work, changes of \pm 1.0 $\mathrm{eV}$ in VOIP were arbitrarily correlated to changes of $\pm 1.0 \mathrm{~V}$ from a zero reference potential, the latter being taken as the standard VOIP of platinum in vacuo. In the present case, as changes in the $\mathrm{CO}$ geometry coordination as a function of the applied potential are properly known on $\mathrm{Pt}$ (111) [21-24], a new zero potential has been defined by shifting the VOIP $0.93 \mathrm{eV}$ positively from the previous one, in order to reproduce linear coordination on the uncharged Pt (111) surfaces. On the basis of the experimental data related to the positions of the adsorbed $\mathrm{CO}$ electro-oxidation peaks [7-9], a shift of $0.31 \mathrm{~V}$ in the electrode potential correlates to a $0.1 \mathrm{eV}$ shift in the Fermi level of Pt. Under these conditions, the positions of the peaks in the electrochemical spectrum can be associated with the stability of interacting co-adsorbed $\mathrm{Pt}(\mathrm{CO}) \cdot \mathrm{Pt}(\mathrm{OH})$ species.

It should be noted that a one-to-one correlation has been used in other comparathli: situations [22-24,29,30]. XPS measurements of gold electrodes emersed from 
caesium halide-containing solutions exhibit a linear relationship between the gold work function and the applied potential, with a slope equal to unity $[36,37]$. However, it should he noted that the actual shift in the Fermi energy level with the applied potential differs appreciably for different metal/electrolyte interfaces, because the potential shift affects both surface and bulk states [38]. Shifts in surface state energies of $0.3 \mathrm{eV}$ have been measured for a $1.0 \mathrm{~V}$ shift in the bulk states for the $\mathrm{Au}(100) / 0.5 \mathrm{M} \mathrm{NaF}$ system, whereas $3-4 \mathrm{eV} / \mathrm{V}$ work function/applied potential plot slopes have been observed for $\mathrm{Ag}$ (110) in the same solution. On the basis of the influence of the concentration of surface states in the behaviour of adsorbates at the solid electrode surface, the specific work function/applied potential response of each adsorbed layer can easily be understood. Correspondingly, for the $\mathrm{Pt} / \mathrm{CO}$ system it has been estimated that the adsorbate feels about $40 \%$ of the entire potential drop applied to the metal/solution interface [39]. The preceding facts support the election of the correlation between the electro-oxidation potential peaks and the stabilities of the interacting co-adsorbed $\mathrm{Pt}(\mathrm{CO}) \cdot \mathrm{Pt}(\mathrm{OH})$ species.

\section{RESULTS AND INTERPRETATION}

Likely structures for the $\mathrm{CO}$ adsorbed layer related directly to the electro-oxidation reaction

For a particular value of $\theta$ and a selected platinum crystalline face, the structure of the adsorbed layer, as spectroscopically determined for uncharged Pt surfaces, changes with the applied potential (Figs. 2-6). As the potential is set increasingly positive, the $\theta^{\mathrm{T}} / \theta^{\mathrm{B}}$ ratio increases [21,23]. Unfortunately, binding energy calculations for the structures with $\mathrm{OH}$ adsorbed on top sites [40] as depicted in Figs. 2-6 are worthless, because they become extremely sensitive to cluster border effects, as has been found from ab-initio pseudo-potential calculations for $(\mathrm{Pt})_{N}$ clusters [41], where $N$ is the number of metal atoms in the cluster. To circumvent this difficulty, the related local structures for particular values of $\theta$ were built up at the central atom cluster region (Figs. 7 and 8, a, c, e, g). These local structures can represent

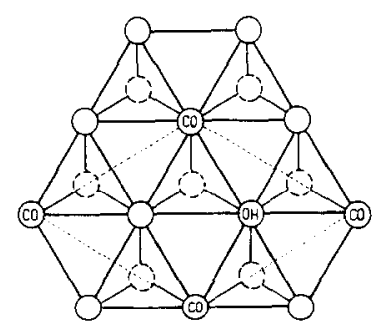

Fig. 2. $(\sqrt{3} \times \sqrt{3})$ R30 LEED pattern corresponding to $\mathrm{CO}$ adsorbed on $\mathrm{Pt}$ (111) for $\theta=0.33$ [1]. The possible $\mathrm{OH}$ adsorption site is also included. The structure of the adsorbed layer remains unaltered under a positive applied potential. 

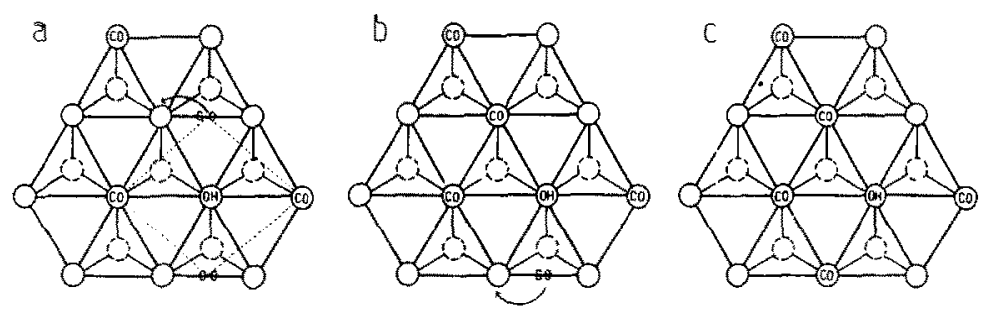

Fig. 3. (a) CO adsorbed on a $\mathrm{Pt}$ (111) uncharged surface for $\theta=0.5$ as derived from the $c(4 \times 2) \mathrm{LEED}$ pattern [1]. The $\mathrm{OH}$ adsorption site is also included. (b, c) Adsorbed structures resulting for a positive applied potential to the initial $\mathrm{c}(4 \times 2)$ structure.
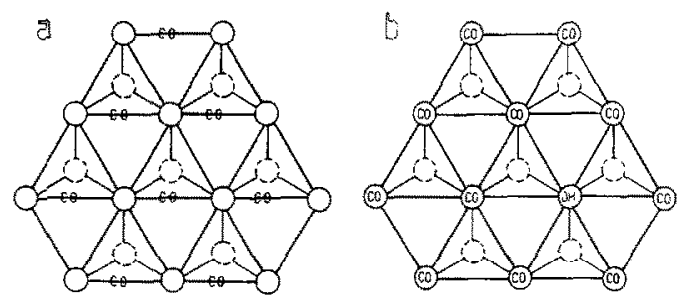

Fig. 4. (a) $\mathrm{CO}^{\mathrm{B}}$ adsorbed structure on an uncharged $\mathrm{Pt}$ (111) surface proposed for $\theta=0.68$ [1]. (b) Adsorbed structure for $\theta=1.0$ and a positive applied potential. A local $(\mathrm{CO})_{\text {ad }}$ vacancy is necessary for $\mathrm{OH}$ adsorption.
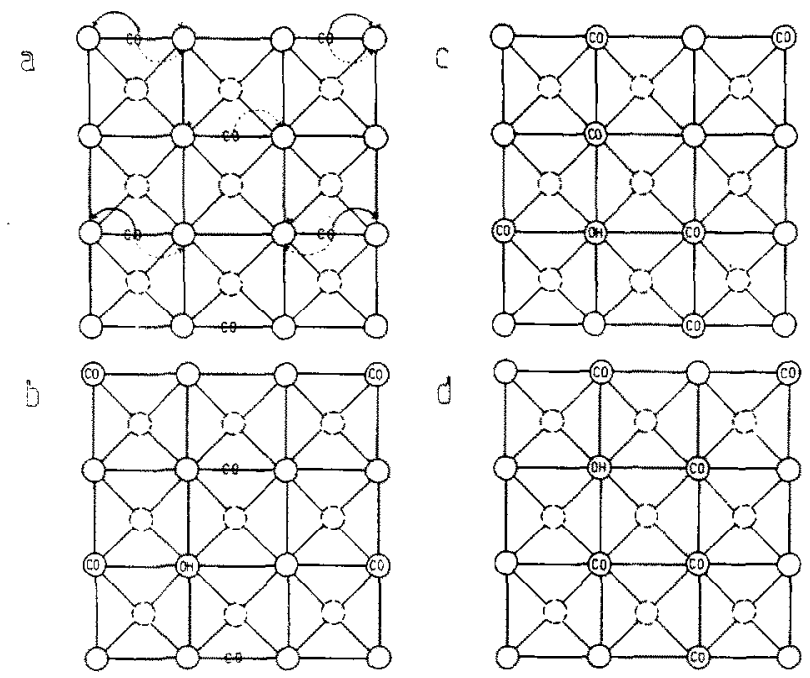

Fig. 5. Possible structures of adsorbed $C O$ on $\mathrm{Pt}(100)$ at $\theta=0.5$. (a) $(2 \times 2)$ LEED pattern derived structure for the uncharged metal surface [5]. (b, c, d) Possible modifications as the potential is changed positively from (a) to (c) (adsorption site is also included. 

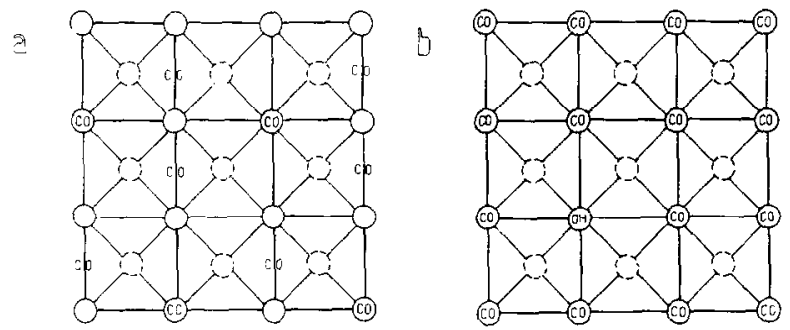

Fig. 6. Structures corresponding to relatively high $\mathrm{CO}$ surface coverages on $\mathrm{Pt}$ (100). (a) Uncharged surface, $\theta=2 / 3$ [5]. (b) Possible structure for increasing coverage and positive potential. A local $(\mathrm{CO})_{\text {ad }}$ vacancy should exist for $\mathrm{OH}$ adsorption.

different adsorbates which are able to participate in the voltammetric electro-oxidation reaction, each one being associated with a particular current peak at a definite applied potential value.
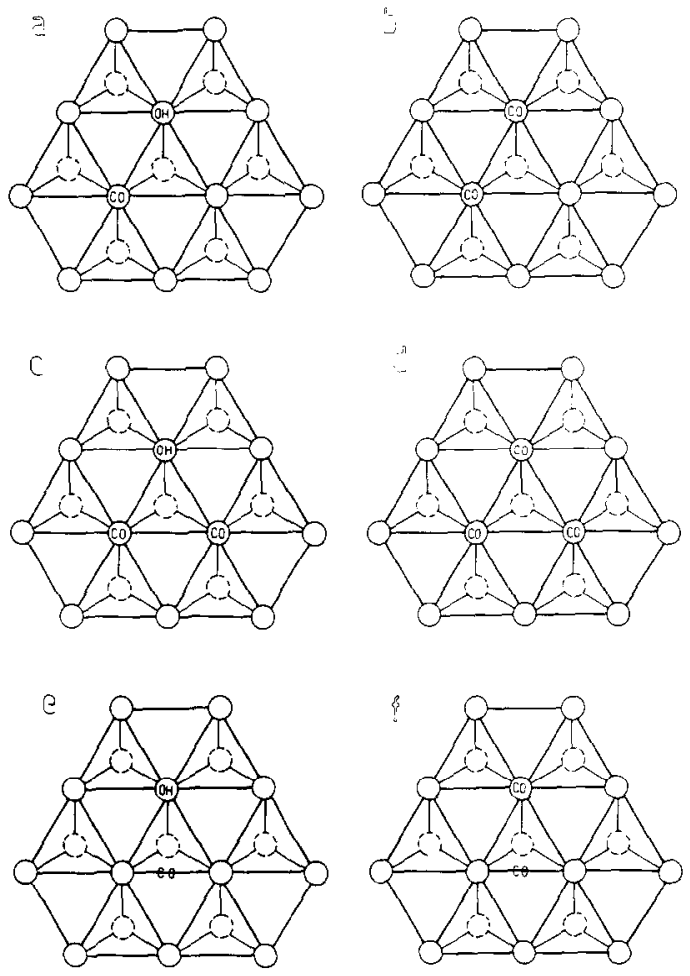

Fig. 7. Local structures involving the central atoms of the cluster. The energies of the various configurations are compared to define the stability inversion potential on $\mathrm{Pt}(111)$. Comparisons between (a) and (b), (c) and (d), and (e) and (f) are made. 
a

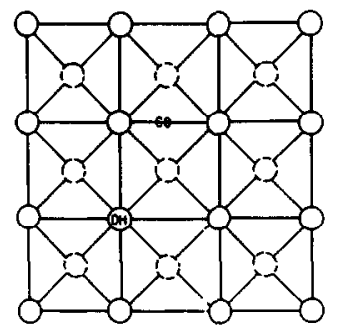

A
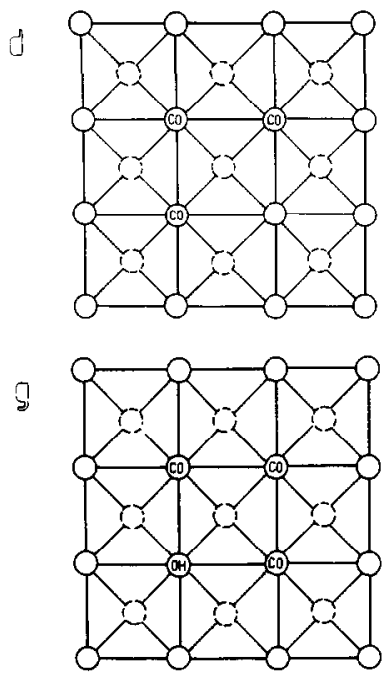

b

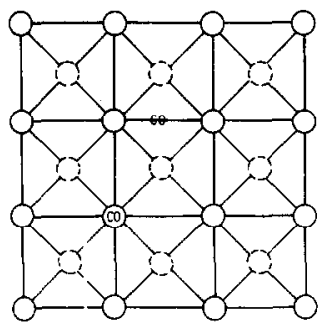

e

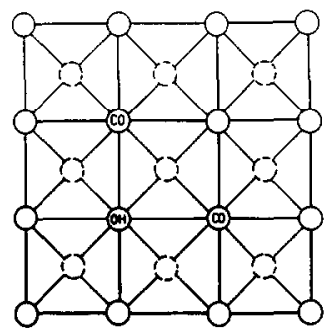

h

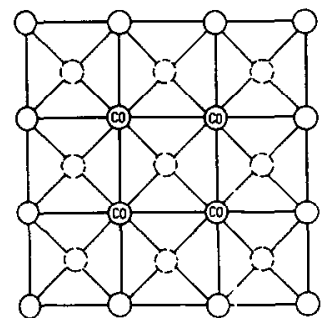

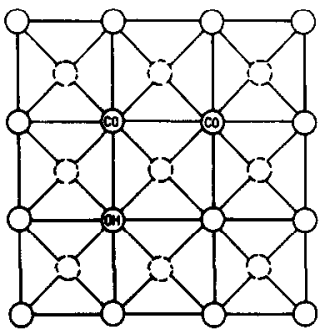

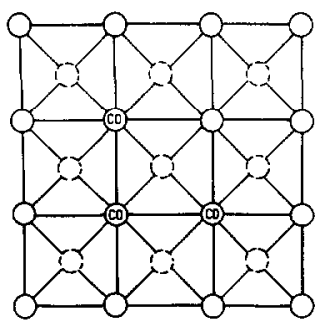

Fig. 8. Local structures involving the central atoms of the cluster. The energies of the various configurations are compared to define the stability inversion potential on $\mathrm{Pt}(100)$. Comparisons between (a) and (b), (c) and (d), (e) and (f), and (g) and (h) are made.

Stability inversion potentials for adsorbates

The influence of the applied electric potential on the stability of the different local structures resulting for values of $\theta$ ranging from 0.33 to 1 (Figs. 7 and 8) can be analysed for both the bridge and the on-top $\mathrm{CO}$ coordination by comparing the stabilities of possible $(\mathrm{Pt})_{N}(\mathrm{CO})_{n}(\mathrm{OH})_{m}$ and $(\mathrm{Pt})_{N}(\mathrm{CO})_{n+m}$ co-adsorbed ensembles, where the stoichiometric coefficients satisfy the condition $(n+m) \leqslant N$ for different electrode potentials. In this way, one observes (Table 2 ) that as the stability of the $(\mathrm{Pt})_{N}(\mathrm{CO})_{n+m}$ ensemble becomes greater than that of the $(\mathrm{Pt})_{N}(\mathrm{CO})_{n}(\mathrm{OH})_{m}$ ensemble for increasing positive potential, the value of the $\mathrm{Pt}(\mathrm{CO}) \cdot \mathrm{Pt}(\mathrm{OH})$ interaction energy favours $\mathrm{CO}_{2}$ desorption [9].

The $\mathrm{BE}$ values for $\mathrm{CO}$ and $\mathrm{OH}$ co-adsorption, and accordingly the stabilities of the co-adsorbed structures themselves, change continuously as the potential increases from 0.4 to $1.2 \mathrm{~V}$ (Figs. 7 and 8). As the potential is increased positively, the adsorbed structures a, c, e and $\mathrm{g}$ in Figs. 7 and 8 become less stable than structures 
TABLE 2

Correspondence between SIP (theoretical) expressed as $H_{6 s 6 s \mathrm{Pl}}$, and the potentials of the voltammetric peaks (experimental) related to the electro-oxidation of different $\mathrm{CO}$ adsorbates (Figs. 7-8 and 9-10, respectively). The BE differences between each pair of structures, indicated in the last column for each $H_{6 s 6 s \mathrm{Pt}}$ value, show the accuracy of the results

\begin{tabular}{|c|c|c|c|}
\hline & $\begin{array}{l}\text { Electro-oxidation potential } \\
\text { (experimental) } \\
/ \mathrm{V}\end{array}$ & $\begin{array}{l}\text { SIP valucs } \\
\text { (theoretical) } \\
/ \mathrm{eV}\end{array}$ & $\begin{array}{l}\text { BE } \\
\text { differences } \\
/ \mathrm{eV}\end{array}$ \\
\hline \multicolumn{4}{|l|}{$\mathrm{Pt}(111) \cdot \mathrm{CO}^{\mathrm{T}}$} \\
\hline $\begin{array}{l}\text { Fig. } 7, \mathrm{a}, \mathrm{b} \\
\mathrm{Pt}(111) \cdot \mathrm{CO}^{\mathrm{T}}\end{array}$ & 0.83 & -11.20 & +0.008 \\
\hline $\begin{array}{l}\text { Fig. } 7, \mathrm{c}, \mathrm{d} \\
\operatorname{Pt}(111) \cdot \mathrm{CO}^{\mathrm{B}}\end{array}$ & 0.98 & -11.26 & -0.001 \\
\hline $\begin{array}{l}\text { Fig. } 7, \mathrm{e}, \mathrm{f} \\
\mathrm{Pt}(100) \cdot \mathrm{CO}^{\mathrm{T}}\end{array}$ & 1.20 & -11.32 & +0.005 \\
\hline $\begin{array}{l}\text { Fig. } 8, \mathrm{c}, \mathrm{d} \\
\mathrm{Pt}(100) \cdot \mathrm{CO}^{\mathrm{T}}\end{array}$ & 0.80 & -11.19 & -0.006 \\
\hline $\begin{array}{l}\text { Fig. } 8, \mathrm{e}, \mathrm{f} \\
\mathrm{Pt}(100) \cdot \mathrm{CO}^{\mathrm{T}}\end{array}$ & 0.98 & -11.26 & +0.001 \\
\hline Fig. $8, \mathrm{~g}, \mathrm{~h}$ & 1.08 & -11.28 & -0.002 \\
\hline
\end{tabular}

$\mathrm{b}, \mathrm{d}, \mathrm{f}$ and $\mathrm{h}$, respectively. On the basis of these results, it is possible to define a stability inversion potential (SIP) at which a structure containing two different near-neighbour adsorbates, i.e. $(\mathrm{CO})_{\text {ad }}(\mathrm{OH})_{\text {ad }}$ (Figs. 7 and 8, a, c, e, g), changes to a structure containing only a single adsorbate, i.e. $(\mathrm{CO})_{\text {ad }}$ (Figs. 7 and $8, \mathrm{~b}, \mathrm{~d}, \mathrm{f}, \mathrm{h}$ ). The SIP values related to the different structural changes can be correlated directly to the potentials of the various voltammetric peaks [7-9] for the electro-oxidation of $\mathrm{CO}$ adsorbates on different $\mathrm{Pt}$ single crystals to $\mathrm{CO}_{2}$ in acid solution (Table 2).

Calculations made for the adsorbates on the Pt (111) cluster indicate that there are three different values of the SIP, and that the desorption of $(\mathrm{CO})^{\mathrm{B}}$ in this case occurs at a potential more positive than that for $(\mathrm{CO})^{\mathrm{T}}$. On the other hand, similar calculations carried out for the $\mathrm{Pt}(100)$ cluster result in four values of the SIP and the desorption of $(\mathrm{CO})^{\mathrm{B}}$ occurs at a potential less positive than that for $(\mathrm{CO})^{\mathrm{T}}$.

From the data assembled in Table 2 on can conclude that there is fairly good agreement between the potentials of the different voltammetric peaks for adsorbed CO electro-oxidation on Pt (111) and on Pt (100) (Figs. 9 and 10) and the SIP values. However, it should be noted that the assignments of each peak to a particular type of adsorbate, as resulting from voltammetry [42], differ to some extent from those derived from the EHM calculation.

(a) The Pt (111) cluster substrate

The $(\sqrt{3} \times \sqrt{3})$ R30 structure (Fig. 2) resulting on Pt (111) for $\theta=0.33$ is compatible only with interactions between $\mathrm{Pt}(\mathrm{OH})_{\text {ad }}^{\mathrm{T}}$ and $\mathrm{Pt}(\mathrm{CO})_{\mathrm{ad}}^{\mathrm{T}}$ (Fig. 7, a, b). Therefore, in this case a single electro-oxidation voltammetric peak located at the less positive potential, i.e. $0.8 \mathrm{~V}$ (Fig. 9), should be expected. 


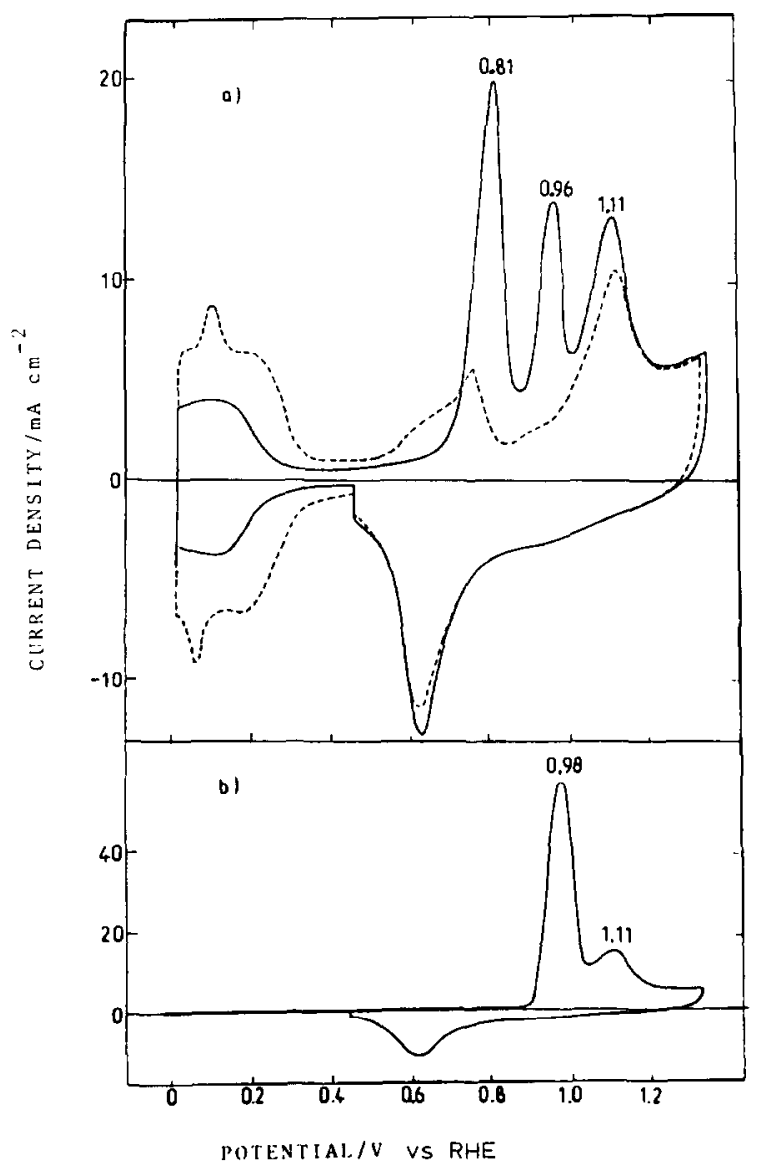

Fig. 9. Voltammograms of a $\mathrm{Pt}$ (111) single-crystal plane electrode in a $\mathrm{CO}$-saturated solution $(0.5 \mathrm{M}$ $\mathrm{HClO}_{4}, 25^{\circ} \mathrm{C}, 10 \mathrm{~V} \mathrm{~s}^{-1}$ ); $E_{\text {ads }}=0.45 \mathrm{~V}$ (vs. RHE). (a) Adsorption time, $\tau=2.6 \mathrm{~s}(\longrightarrow$ ), and hlank electrolyte $(---)$; (b) adsorption time, $\tau=25 \mathrm{~s}$. From ref. 8, by permission of Elsevier Science Publishers B.V.

The $c(4 \times 2)$ structure resulting for Pt (111) at intermediate values of $\theta$ (Fig. 3a) indicates at least two kinds of interactions (Fig. 7, a, e). Accordingly, it is possible, in principle, that if the coordination geometry of the $\mathrm{CO}$ adsorbate remains independent of the applied potential, only two voltammetric peaks should be observed. Conversely, for a potential-dependent coordination geometry of the $\mathrm{CO}$ adsorbate (Fig. 3, b, c), the number of peaks should be greater than two as the local structures represented in Figs. 7a, $c$ and e can be generated. The latter situation can explain the three voltammetric peaks which are observed under the conditions described for Fig. 9.

According to the data assembled in Table 2, the voltammetric peak at $0.8 \mathrm{~V}$ can be assigned to a reactant involving the $(\mathrm{CO})_{\mathrm{ad}}^{\mathrm{T}} \cdot(\mathrm{OH})_{\mathrm{ad}}^{\mathrm{T}}($ Fig. 7a) ensemble. Like- 


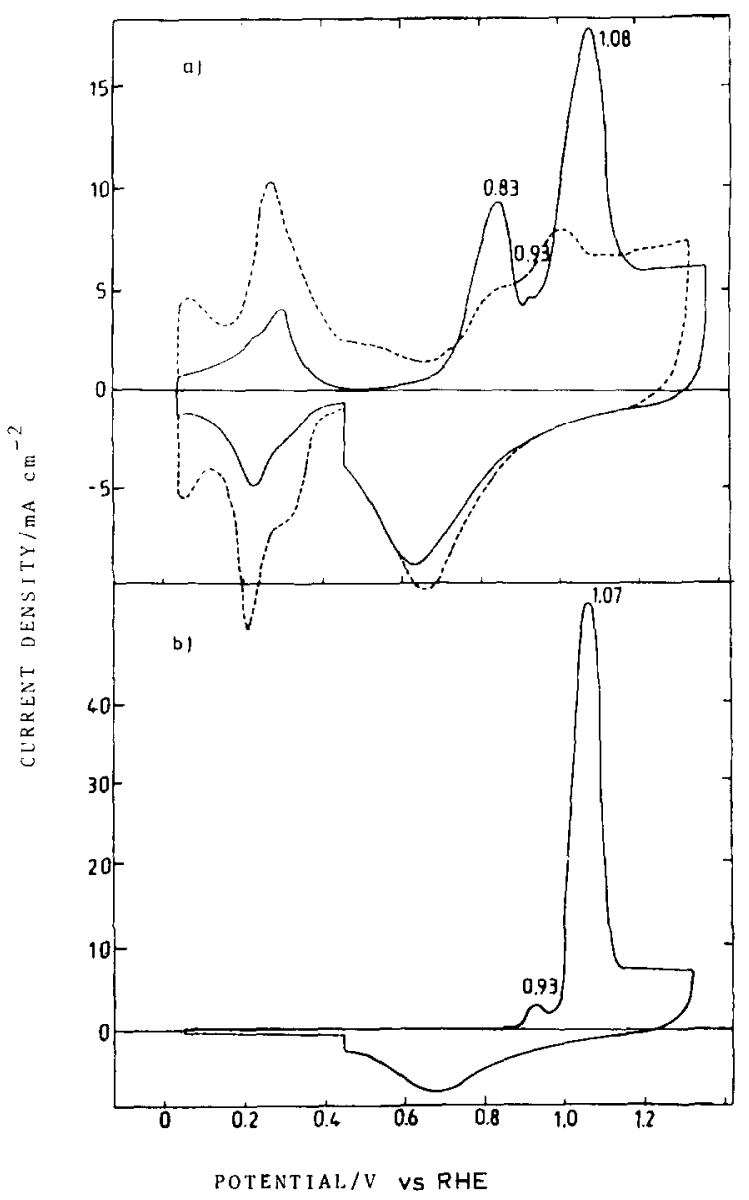

Fig. 10. Voltammograms of a $\mathrm{Pt}(100)$ single-crystal plane electrode in a CO-saturated solution $(0.5 \mathrm{M}$ $\left.\mathrm{HClO}_{4}, 25^{\circ} \mathrm{C}, 10 \mathrm{~V} \mathrm{~s}^{-1}\right) ; E_{\text {ads }}=0.45 \mathrm{~V}$ (vs. RHE). (a) Adsorption time, $\tau=2.8 \mathrm{~s}(-$ - $)$, and blank electrolyte (- - ); (b) adsorption time, $\tau=20 \mathrm{~s}$. From ref. 8, by permission of Elsevier Science Publishers B.V.

wise, the same kind of interaction can be extended to a larger ensemble such as $\left.\left((\mathrm{CO})_{a d}^{\mathbf{T}}\right)_{2}(\mathrm{OH})_{\mathrm{ad}}^{\mathrm{T}}\right)$ (Fig. 7c). The latter configuration can be explained as one which is associated with a certain range of the applied potential, and it presumably gives rise to the electro-oxidation peak at $0.98 \mathrm{~V}$. Similarly, the electro-oxidation of the $(\mathrm{CO})_{\mathrm{ad}}^{\mathrm{B}}(\mathrm{OH})_{\text {ad }}^{\mathrm{T}}$ ensemble (Fig. 7e) would account for the peak observed at about 1.2 $\mathrm{V}$. Nevertheless, it should be considered that, at high positive potentials, it is likely that an $(\mathrm{O})_{\mathrm{ad}}$ species instead of $(\mathrm{OH})_{\mathrm{ad}}$ is related to the electro-oxidation mechanism of $\mathrm{CO}$ adsorbates. On the other hand, when $\theta=1$, the relatively large positive potential should modify the adsorbate structure, yielding a single structured, uni- 
formly distributed adsorbate (Fig. 4b) which favours the appearance of a single electro-oxidation peak at $0.98 \mathrm{~V}$.

In conclusion, the voltammetric peak multiplicity associated with different values of $\theta$ on $\mathrm{Pt}$ (111) can be explained through distinguishable applied potential-dependent reactant structures emerging from $(\mathrm{CO})_{\mathrm{ad}}^{\mathrm{T}} \cdot(\mathrm{OH})_{\mathrm{ad}}^{\mathrm{T}}$ ensembles with different $(\mathrm{CO})_{\mathrm{ad}}^{\mathrm{T}} /(\mathrm{OH})_{\mathrm{ad}}^{\mathrm{T}}$ ratios.

\section{(b) The Pt (100) cluster substrate}

$\mathrm{CO}$ adsorbed on $\mathrm{Pt}(100)$ produces a $c(2 \times 2)$ LEED pattern for $\theta=0.5$ at the uncharged metal surface. The starting $c(2 \times 2)$ structure (Fig. 5a) changes as the applied potential is shifted positively by producing adsorbate structures such as those depicted in Figs. $5 b$, c and $d$ which are constituted by $(\mathrm{CO})_{a d}^{\mathrm{B}}(\mathrm{OH})_{\mathrm{ad}}^{\mathrm{T}}$ and $(\mathrm{CO})_{\mathrm{ad}}^{\mathrm{T}}(\mathrm{OH})_{\mathrm{ad}}^{\mathrm{T}}$ ensembles. For Pt $(100)$, those ensembles involving $(\mathrm{CO})_{\mathrm{ad}}^{\mathrm{B}}$ and $(\mathrm{OH})_{\mathrm{ad}}^{\mathrm{T}}$ (Fig. 8a) become unstable, i.e. as the threshold potential for the $(\mathrm{OH})_{\mathrm{ad}}^{\mathrm{T}}$ formation is reached, $\mathrm{CO}$ desorption takes place immediately. On the other hand, when the applied potential modifies the structure of the adsorbate, the latter gives rise to distinguishable desorption peaks which can be correlated to the configurations illustrated in Figs. 5c and d. The SIP values of these configurations derived from the interactions indicated in Figs. 8c, e and $\mathrm{g}$ correlate with the following potential values of the voltammetric peaks: $0.8,0.98$ and $1.08 \mathrm{~V}$ (see Table 2).

Obviously, for increasingly positive applied potentials and greater values of $\theta$ the $c(4 \times 2)$ structure changes as depicted in Fig. 6 . Thus, for $\theta=1$, as a result of the interaction described in Fig. 8g, the SIP value correlates with $1.08 \mathrm{~V}$, a figure which agrees with the peak potential value found experimentally. Furthermore, it should be noted that for $\theta=1$ the voltammetric peak located at $1.08 \mathrm{~V}$ becomes much narrower than that appearing at $1.07 \mathrm{~V}$ for $\theta=0.5$ (Fig. 10). At intermediate values of $\theta$, different interactions can contribute to the adsorbate desorption so that it starts at $0.98 \mathrm{~V}$, giving rise to a peak located at $1.07 \mathrm{~V}$. The latter should be considered as the envelope of at least two peaks. Nevertheless, for $\theta \simeq 1$ a single type of cooperative interaction exists and therefore there is a single peak at 1.08 , not preceded by any desorption feature.

\section{(c) Conclusions from the EHM calculations}

The EHM calculations combined with the mechanistic information reported recently [7-9] furnish, for the first time, concrete data related to the stabilities of the different CO-containing adsorbates which can be formed on Pt (111) and Pt (100) clusters. These calculations provide the basis for a structural interpretation of the adsorbed $\mathrm{CO}$ electro-oxidation reaction on Pt single crystals. The theoretical results also indicate that for sufficiently positive potentials, new adsorbate structures are obtained which, in principle, are comparable to those which have been determined spectroscopically for the uncharged $\mathrm{Pt} / \mathrm{CO}$ (gas phase) system. According to the present EHM approach, the multiplicity and location of the voltammetric current peaks related to the electro-oxidation of $\mathrm{CO}$ adsorbates on platinum are not exclusively the results of different adsorbate coordination geometries, but should be 
mainly the result of cooperative interactions [43] involving $\mathrm{OH}$ co-adsorbed with different numbers of linearly adsorbed $\mathrm{CO}$ molecules at particular crystalline faces.

\section{Molecular orbital interpretation}

The CO-Pt adsorption bond, both for linear and for bi-coordinated adsorbate geometries, is the result of the delocalization of the $5 \sigma$ orbital of $\mathrm{CO}$ on the $d$ band of $\mathrm{Pt}$, and the simultaneous back-donation to $\pi^{*} \mathrm{CO}$ orbitals. Bonding and antibonding interactions are also involved in $\mathrm{OH}$ adsorption [31] (Figs. 11 and 12). A decrease in the energy of the Fermi level for increasing positive applied potentials strengthens the $(\mathrm{CO})^{\mathrm{T}}$ bonding to the surface through a more effective stabilization of $5 \sigma$ orbitals, whereas for $\mathrm{OH}$ adsorption the opposite effect results as the antibonding interaction becomes more relevant.

Let us consider the cooperative interactions of co-adsorbed $\mathrm{CO}$ and $\mathrm{OH}$ on platinum. Experimental data [9] indicate that the $\mathrm{CO}$ adsorption threshold potential is $0.4 \mathrm{~V}$, and that water molecule electrodecomposition yielding adsorbed $\mathrm{OH}$ species has already begun at $0.6 \mathrm{~V}$. Therefore, the adsorption of $\mathrm{OH}$ species on platinum starts when the surface is already largely covered by $(\mathrm{CO})^{\mathrm{T}}$ adsorbates.

The stabilization of $\mathrm{OH}$ orbitals through bonding interaction occurs similarly for both $(\mathrm{Pt})_{N}(\mathrm{CO})_{n}(\mathrm{OH})$ and $(\mathrm{Pt})_{N}(\mathrm{OH})$. Perturbative interactions involving $\mathrm{OH}$ and pre-adsorbed $\mathrm{CO}$ destabilize the antibonding $\mathrm{Pt} \cdot \mathrm{OH}$ orbital levels, a fact which

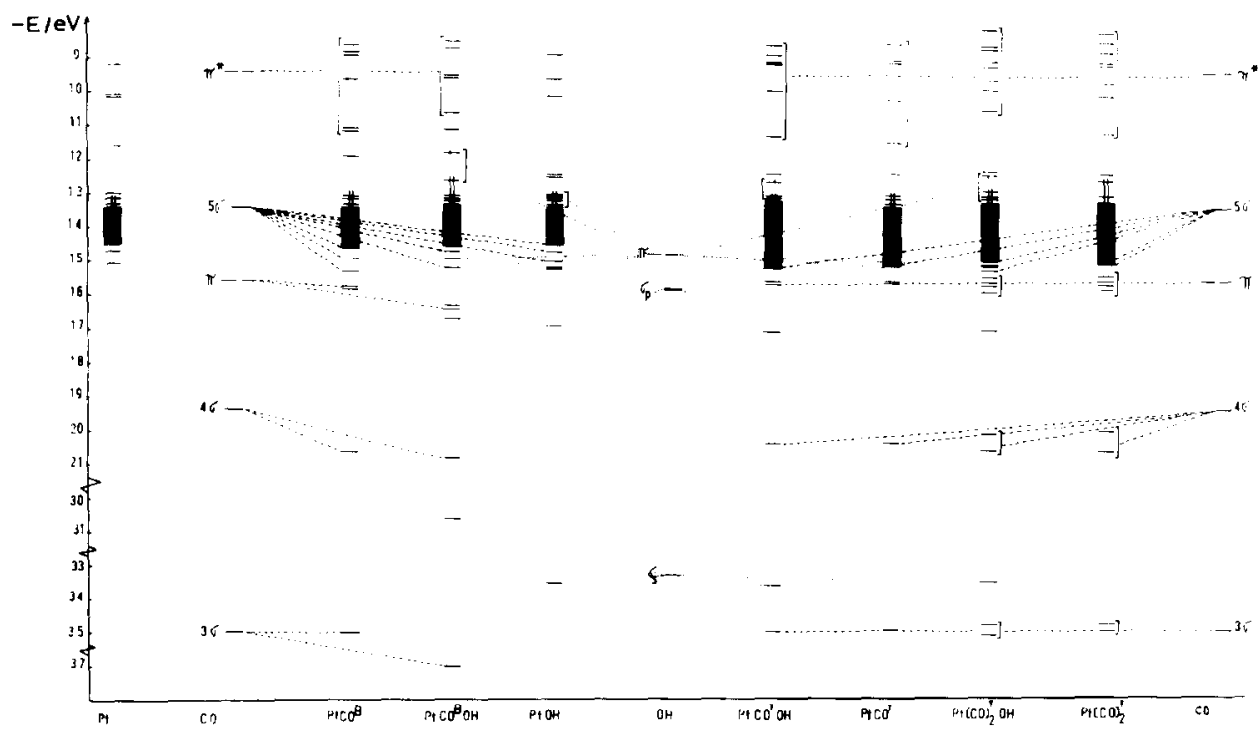

Fig. 11. Molecular orbital correlation diagrams for the adsorption of $(\mathrm{CO})_{n}(0 \leqslant n \leqslant 2)$ and $(\mathrm{OH})$ on $\mathrm{Pt}$ (111) $\left(H_{6 s 6 s \mathrm{Pt}}=-11.20 \mathrm{eV}\right) \cdot \mathrm{CO}^{\mathrm{B}}$ : bridge-bonded $\mathrm{CO}$ (Fig. 7e). $\mathrm{CO}^{\mathrm{T}}$ : linearly bonded $\mathrm{CO}$ (Figs. 7a, c). $(\cdots \mathrm{OH})$ Interactions with $(\mathrm{Pt})_{19}$ energy levels; $(-\ldots-\mathrm{CO})$ interactions with $(\mathrm{Pt})_{19}$ energy levels. 


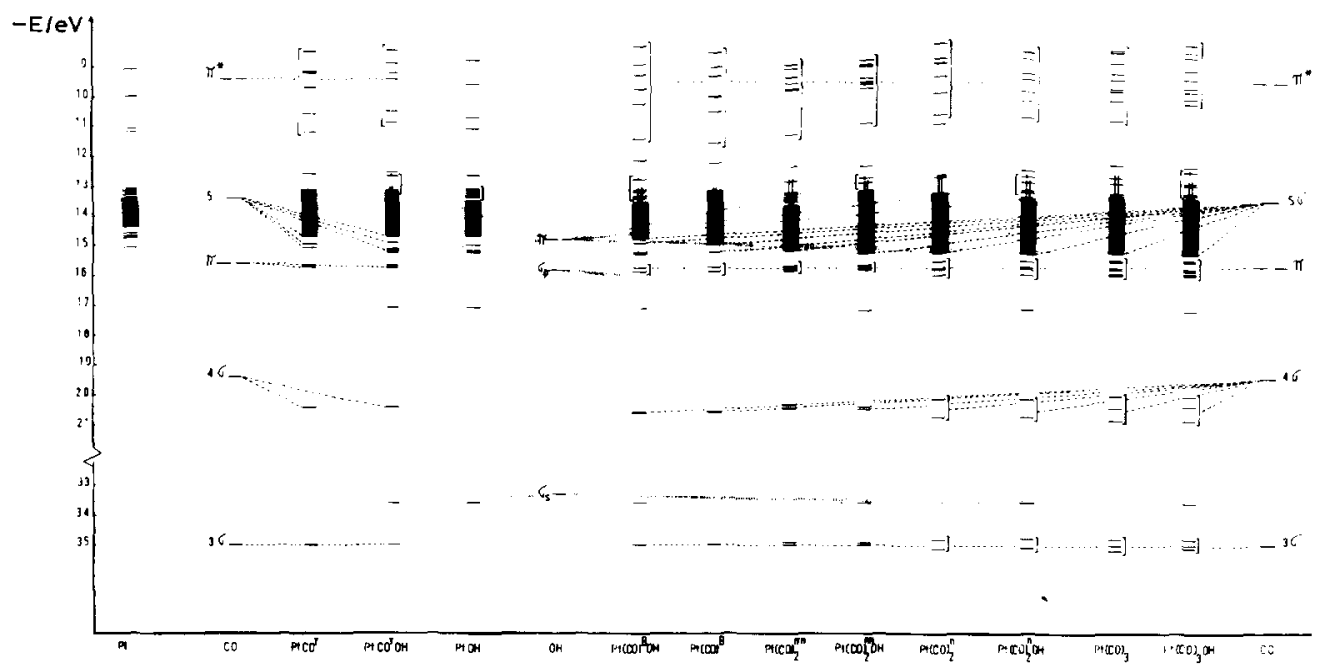

Fig. 12. Molecular orbital correlation diagrams for the adsorption of $(\mathrm{CO})_{n}(0 \leqslant n \leqslant 3)$ and $\mathrm{OH}$ on $\mathrm{Pt}$ (100) $\left(H_{6 s 6 s \mathrm{Pt}}=-11.20 \mathrm{eV}\right) \cdot \mathrm{CO}^{\mathrm{B}}$ : bridge-bonded $\mathrm{CO}$ (Fig. 8a). $\mathrm{CO}^{\mathrm{nn}}:$ non-neighbour linearly bonded $\mathrm{CO}$ (Fig. 8e). $\mathrm{CO}^{\mathrm{n}}$ : neighbour linearly bonded $\mathrm{CO}$ (Fig. 8c). $\mathrm{CO}$ is always linearly bonded unless otherwise stated. $(\cdots \mathrm{OH})$ Interactions with $(\mathrm{Pt})_{25}$ energy levels; $(---\mathrm{CO})$ interactions with $(\mathrm{Pt})_{25}$ energy levels.

allows us to understand that $\mathrm{OH}$ becomes more strongly bonded as $n$, the number of $\mathrm{CO}$ molecules in the adsorbate ensemble, increases. Thus, for a given potential and metal surface structure (Figs. 11 and 12), comparison of the adsorptive stabilization energies for $\mathrm{OH}$ on $(\mathrm{Pt})_{N},(\mathrm{Pt})_{N}(\mathrm{CO})^{\mathrm{T}}$ and $(\mathrm{Pt})_{N}(\mathrm{CO})_{2}^{\mathrm{T}}$ reveals an increasing stability for the adsorbed ensemble produced by the less effective $\mathrm{OH}$ antibonding interaction.

On the other hand, the energy of the Fermi level decreases with increasing positive applied potentials (positive charge). Accordingly, the stabilities of the adsorbed ensembles decrease on increasing the strength of the antibonding interaction, leading to desorption of the adsorbed structures for a certain positive potential value. Consequently, the different adsorbed ensembles should exhibit stabilization energies which, in any case, increase according to $n$. Hence, a definite threshold potential should be associated with the desorption condition of each particular ensemble. Accordingly, the greater the value of $\theta$, the higher the applied potential required for oxidative desorption of the adsorbate.

The calculations show that the adsorbate-adsorbate interactions within each ensemble, either $(\mathrm{Pt})_{N} \mathrm{CO} \cdot \mathrm{OH}$ or $(\mathrm{Pt})_{N} \mathrm{CO} \cdot \mathrm{CO}$, depend, as expected, on the distance between the interacting species. As the interactions between adjacent $\mathrm{CO}$ adsorbates (Fig. 8c) are stronger than those for non-adjacent species (Fig. 8e) the potential required to electrodesorb $\mathrm{CO}$ from the ensemble as $\mathrm{CO}_{2}$, shown in Fig. 8c, becomes necessarily higher than that for desorption from the ensemble depicted in Fig. 8e. On the other hand, the dependence of the perturbative interactions on the 
distance can immediately explain the surprisingly different oxidizing desorption potentials of $(\mathrm{CO})_{\mathrm{ad}}^{\mathrm{B}}$ and $(\mathrm{CO})_{\mathrm{ad}}^{\mathrm{T}}$ on $\mathrm{Pt}(100)$ and $\mathrm{Pt}(111)$. The interaction energies resulting for the $(\mathrm{Pt})_{N}(\mathrm{CO})^{\mathrm{B}}(\mathrm{OH})$ and $(\mathrm{Pt})_{N}(\mathrm{CO})^{\mathrm{T}}(\mathrm{OH})$ ensembles, although they are similar on Pt (100) (Fig. 12), become sufficiently small to stabilize the $\mathrm{OH}$ adsorbate at potentials lying in the range of the electro-oxidation potential of the $\mathrm{CO}$ adsorbate. Otherwise, the interaction energy for the $(\mathrm{Pt})_{N}(\mathrm{CO})^{\mathrm{B}}(\mathrm{OH})$ ensemble on Pt (111) (Fig. 11) generates an extremely stable ensemble, so that the oxidizing desorption potential falls in the potential range where $(\mathrm{O})_{\text {ad }}$ species, instead of adsorbed $(\mathrm{OH})$, exist on platinum [9]. Accordingly, in this case it appears to be more reasonable to assign the voltammetric peak at $1.11 \mathrm{~V}$ to a surface oxidative mechanism involving $(\mathrm{O})_{\text {ad }}$ and $(\mathrm{CO})_{a d}$, instead of the $(\mathrm{CO})^{\mathrm{B}}(\mathrm{OH})$ adsorbate.

In conclusion, this work offers, for the first time, energy values related to different adsorbate ensembles involving $\mathrm{CO}$ adsorbed on $\mathrm{Pt}$ which have been obtained by applying the EHM and by considering the influence of the potential applied to the electrode. These energy values are linearly related to the voltammetric peak potentials resulting for the electro-oxidation of adsorbed $\mathrm{CO}$ on $\mathrm{Pt}$ single crystals in acid solutions. This approach can certainly be improved, and will be useful for discovering possible intermediate structures involved in electrocatalytic reactions and for distinguishing, on a structural basis, between real catalytic intermediates and catalytic poisons for the oxidizing reaction [44].

\section{ACKNOWLEDGEMENTS}

This research project was supported financially by the Consejo Nacional de Investigaciones Científicas y Técnicas and the Comisión de Investigaciones Científicas de la Provincia de Buenos Aires.

\section{REFERENCES}

1 H. Steininger, S. Lehwald and H. Ibach, Surf. Sci., 123 (1982) 264.

2 L.K. Verheij, L. Lux, A.B. Anton, B. Poetsema and G. Comsa, Surf. Sci., 182 (1987) 390.

3 A.M. Lahee, J.P. Trennies and C. Wöll, Surf. Sci., 177 (1986) 371.

4 J.P. Biberian and M.A. Van Hove, Surf. Sci., 118 (1982) 443.

5 J.P. Biberian and M.A. Van Hove, Surf. Sci., 138 (1984) 361.

6 S. Ishi, Y. Ohno and B. Viswanathan, Surf. Sci., 161 (1985) 349.

7 J.M. Léger, B. Beden, C. Lamy and S. Bilmes, J. Electroanal. Chem., 170 (1984) 305.

8 B. Beden, S. Bilmes, C. Lamy and J.M. Léger, J. Electroanal. Chem., 149 (1983) 295.

9 S.A. Bilmes and A.J. Arvia, J. Electroanal. Chem., 198 (1986) 137.

10 J.M. Léger, B. Beden and C. Lamy, Ber. Bunsenges. Phys. Chem., 91 (1987) 336.

11 B. Beden, A. Bewick, K. Kunimatsu and C. Lamy, J. Electroanal. Chem., 142 (1982) 345.

12 A.B. Anderson and M.K. Awad, J. Am. Chem. Soc., 107 (1985) 7854.

13 S. Gilman, J. Phys. Chem., 66 (1962) 2657.

14 S. Gilman, J. Phys. Chem., 67 (1963) 68.

15 S. Gilman, J. Phys. Chem., 67 (1963) 1898.

16 S. Gilman, J. Phys. Chem., 68 (1964) 70.

17 S.B. Brummer and J.I. Ford, J. Phys. Chem., 69 (1965) 1355.

18 T.B. Warner and S. Schuldiner, J. Electrochem. Soc., 111 (1964) 992. 
19 C.H. Hamann, Ber. Bunsenges. Phys. Chem., 75 (1971) 542.

20 P.A. Thiel and T.E. Madey, Surface Science Reports, Vol. 7, Nos. 6-8, 1987, p. 374.

21 E.L. Garfunkel, J.E. Crowell and G.A. Somorjai, J. Phys. Chem., 86 (1982) 310.

22 S.P. Mehandru and A.B. Anderson, J. Phys. Chem., 93 (1989) 2044.

23 N.K. Ray and A.B. Anderson, Surf. Sci., 125 (1983) 803.

24 N.K. Ray and A.B. Anderson, J. Phys. Chem., 86 (1982) 4851.

25 A.M. Castro Luna, M.C. Giordano and A.J. Arvia, J. Electroanal. Chem., 259 (1989) 173.

26 R. Hoffmann, J. Chem. Phys., 39 (1963) 1397.

27 J. Howell, A. Rossi, A. Wallace, K. Horaki and R. Hoffmann, Quantum Chemistry Program Exchange No. 344.

28 J.M. Ammeter, H.B. Bürgi, R.C. Thibeault and R. Hoffmann, J. Am. Chem. Soc., 100 (1978) 3686.

29 G.L. Estiú, S.A. Maluendes, E.A. Castro and A.J. Arvia, J. Phys. Chem., 92 (1988) 2512.

30 G.L. Estiú, S.A. Maluendes, E.A. Castro and A.J. Arvia, J. Electroanal. Chem., in press.

31 A.B. Anderson and N.K. Ray, J. Phys. Chem., 86 (1982) 488.

32 A.B. Anderson and D.P. Onwood, Surf. Sci., 154 (1985) L261.

33 L.W. Anders, R.S. Hansen and L.S. Bartell, J. Chem. Phys., 59 (1973) 5277.

34 G.L. Estiú and S.A. Maluendes, Z. Phys. Chem., in press.

35 C. Minot, B. Bigot and A. Hariti, J. Am. Chem. Soc., 108 (1986) 196.

36 E.R. Kötz, H. Neff and K. Müller, J. Electroanal. Chem., 215 (1986) 331.

37 D.M. Kolb, D.L. Rath, R. Wille and W.N. Hansen, Ber. Bunsenges. Phys. Chem., 87 (1983) 1108.

38 W. Boeck and D.M. Kolb, Surf. Sci., 118 (1982) 613.

39 S. Holloway and J.K. Norskov, J. Electroanal. Chem., 161 (1984) 193.

40 A.B. Anderson, Surf. Sci., 105 (1981) 159.

41 A. Gavezzotti, G.F. Tartadini and H. Miessner, J. Phys. Chem., 92 (1988) 872.

42 S.A. Bilmes, N.R. de Tacconi and A.J. Arvia, J. Electroanal. Chem., 164 (1984) 129.

43 S.A. Bilmes, M.C. Giordano and A.J. Arvia, J. Electroanal. Chem., 225 (1987) 183; Can. J. Chem., 66 (1988) 2259.

44 C. Lamy, B. Beden, N.R. de Tacconi and A.J. Arvia, Electrochim. Acta, in press. 